\title{
Somatosensory evoked potentials after multisegmental lower limb stimulation in focal lesions of the lumbosacral spinal cord
}

Domenico Restuccia, Angelo Insola, Massimiliano Valeriani, Valter Santilli, Letizia Bedini, Domenica Le Pera, Carmen Barba, Francesco Denaro, Pietro Tonali
Department of Neurology, Università Cattolica del Sacro Cuore, Roma, Italy D Restuccia M Valeriani

D Le Pera

C Barba

P Tonali

Department of

Neurophysiology,

CTO, Roma, Italy

A Insola

L Bedini

Spinal Unit

V Santilli

Department of

Neurosurgery

F Denaro

Correspondence to: Dr D Restuccia, Department of Neurology, Pol A Gemelli, L go A Gemelli 8, 00168

Rome, Italy

drestuccia@pelagus.it

Received 17 August 1999 and in revised form

10 January 2000

Accepted 21 January 2000

\begin{abstract}
Objectives-Recording techniques permit the separate analysis of the response from cauda equina roots and the spinal potential that is probably generated by the activation of dorsal horn cells. To improve the functional assessment of focal lesions of the lumbosacral cord, lower limb somatosensory evoked potentials (SEPs) were measured by multisegmental stimulation. Methods-Common peroneal and tibial nerves SEPs were recorded in 14 patients in whom MRI demonstrated compressive cord damage ranging from $\mathrm{T} 9$ to $\mathrm{L} 1$ levels. SEPs were recorded in each patient at the lumbar level (cauda equina response), lower thoracic level (spinal response), and from the scalp (cortical response). Results-Abnormalities in spinal response occurred in $50 \%$ and $70 \%$ of tibial and common peroneal nerve SEPs respectively; these findings were well explained by the radiological compression level, involving in most of the patients lumbar rather than sacral myelomeres. The SEPs were often more effective than the clinical examination in showing the actual extension of damage.

Conclusions-The recording of spinal SEPs after multisegmental lower limb stimulation proved useful in assessing cord dysfunction and determining the cord levels mainly involved by the compression.

(F Neurol Neurosurg Psychiatry 2000;69:91-95)
\end{abstract}

Keywords: somatosensory evoked potentials; spinal cord; lower limb

It has already been shown that the recording of spinal as well as root somatosensory evoked potentials (SEPs) after lower limb stimulation can be helpful in the functional assessment of lumbar cord lesions. ${ }^{1-4}$ The functionality of the central grey matter at the level of the lumbar enlargement can be explored by recording the segmental spinal response to electrical stimulation of the lower limb..$^{2-5}$ This response is probably generated by the postsynaptic activation of dorsal horn cells from collateral branches of the ascending somatosensory pathways. ${ }^{67}$ Thus, SEPs should be used when, for example, clinical examination is unable to distinguish signs of lumbar cord involvement from those of lumbar root lesion, or when an objective assessment of the cord dysfunction is needed for monitoring purposes. Nevertheless, as tibial nerve stimulation usually involves the L5 and S1 dermatomes, the recording of the $\mathrm{N} 24$ spinal response can fail in demonstrating a focal lesion of the lumbar enlargement, when this lesion is localised slightly above or below the L5-S1 levels. Therefore, we attempted to improve the diagnostic yield of lower limb SEPs by stimulating not only the tibial, but also the common peroneal nerve at the knee. Multisegmental SEPs might be also useful in defining the functional lesion level when MRI shows multiple levels of compression.

Therefore, we studied both tibial and common peroneal nerve SEPs in 14 patients in whom MRI demonstrated focal compressive lesion of the lumbar spinal ranging from $\mathrm{T} 9$ to L1.

\section{Patients and methods}

PATIENTS

We studied 14 patients (mean age 46.4 (SD 14.1), range 23-72). Spinal MRI was performed in all patients. The MRI studies were performed on superconducting 0.5 or 1.5 tesla units, with sagittal and axial $5 \mathrm{~mm}$ T1 and T2 weighted spin echo slices. Spinal MRI showed vertebral fracture in nine patients and disc herniation in the remaining five.

Cord compression involved:

(1) vertebral segments above T12 (patients 1 and 2)

(2) thoracic spine comprising the 12th vertebral segment (10 patients, Nos 3-12);

(3) lumbar spine always involving the first lumbar vertebra (patients 13 and 14)

Neuroradiological data are summarised in table 1 .

EVOKED POTENTIAL RECORDING PROCEDURE For SEP recording, patients lay on a couch in a warm and semidarkened room. All patients underwent tibial and common peroneal nerve SEPs on both sides. Stimuli ( $0.2 \mathrm{~ms}$ square pulses) were delivered at $5 \mathrm{~Hz}$ using skin electrodes (cathode proximal) at motor threshold intensity. Stimulations were delivered at the popliteal fossa for the common peroneal nerve and at the ankle for the tibial nerve. The filter bandpass was $10-3000 \mathrm{~Hz}(-3 \mathrm{~dB}$ at cut off point, $6 \mathrm{~dB}$ per octave); the analysis time was $100 \mathrm{~ms}$. Samples with excess interference were automatically edited out of the average. Two averages of 2048 trials each were obtained and drawn out by the computer on an HP laserjet printer. 
Table 1 Radiological and SEP findings

\begin{tabular}{|c|c|c|c|c|c|c|c|c|c|c|c|}
\hline \multirow[b]{3}{*}{ Patient } & \multirow[b]{3}{*}{ Age } & \multirow[b]{3}{*}{ Sex } & & & \multicolumn{7}{|c|}{ SEP latencies (ms) } \\
\hline & & & \multicolumn{2}{|l|}{ MRI findings } & \multirow[b]{2}{*}{ Side } & \multicolumn{3}{|c|}{ Common peroneal nerve } & \multicolumn{3}{|c|}{ Tibial nerve } \\
\hline & & & Type of lesion & Level & & $C E$ & N14 & $P 27$ & $C E$ & N24 & P40 \\
\hline \multirow[t]{2}{*}{1} & \multirow[t]{2}{*}{56} & \multirow[t]{2}{*}{ M } & \multirow[t]{2}{*}{ Disc herniation } & \multirow[t]{2}{*}{ D9-D10 } & $\mathrm{R}$ & 11.8 & - & 28 & 19.4 & - & 41.4 \\
\hline & & & & & $\mathrm{L}$ & 11.8 & - & 28.6 & 19.6 & - & 42 \\
\hline \multirow[t]{2}{*}{2} & \multirow[t]{2}{*}{46} & \multirow[t]{2}{*}{ M } & \multirow{2}{*}{ Disk herniation } & \multirow[t]{2}{*}{ D9-D10 } & $\mathrm{R}$ & 11.2 & 14.8 & 36 & 20.8 & 24 & 44 \\
\hline & & & & & $\mathrm{L}$ & 11.6 & 14.6 & 39 & 20.4 & 23.6 & 44.2 \\
\hline \multirow[t]{2}{*}{3} & \multirow[t]{2}{*}{24} & \multirow[t]{2}{*}{ M } & \multirow{2}{*}{ Vertebral fracture } & \multirow{2}{*}{$\mathrm{D} 10, \mathrm{D} 11, \mathrm{D} 12$} & $\mathrm{R}$ & 12.4 & - & - & 19 & 21.8 & - \\
\hline & & & & & $\mathrm{L}$ & 12.2 & - & - & 19.6 & - & - \\
\hline \multirow{2}{*}{4} & \multirow{2}{*}{60} & \multirow{2}{*}{ M } & \multirow{2}{*}{ Vertebral fracture } & \multirow[t]{2}{*}{ D12 } & $\mathrm{R}$ & 12.2 & - & 39.4 & 20 & - & 46 \\
\hline & & & & & $\mathrm{L}$ & 11.4 & - & 39 & 19 & - & 49.6 \\
\hline 5 & 72 & $M$ & Disc herniation & D11-12 & $\mathrm{R}$ & 10.8 & - & 37.4 & 19 & - & 43.5 \\
\hline & & & & & $\mathrm{L}$ & 10.6 & - & 38.4 & 19 & - & 44 \\
\hline 6 & 44 & $M$ & Vertebral fracture & $\mathrm{D} 11, \mathrm{D} 12$ & $\mathrm{R}$ & 11.4 & - & - & 20 & 23.8 & - \\
\hline & & & & & $\mathrm{L}$ & 11.8 & - & - & 21.2 & 24 & - \\
\hline 7 & 55 & $M$ & Vertebral fracture & D12 & $\mathrm{R}$ & 9.4 & 12.4 & - & 19 & 21.6 & - \\
\hline & & & & & $\mathrm{L}$ & 10.4 & - & - & 18.2 & 20.8 & 45.8 \\
\hline 8 & 48 & $\mathrm{~F}$ & Disc herniation & D11-12 & $\mathrm{R}$ & 12 & 15.3 & 36.7 & 19.3 & 23.6 & - \\
\hline & & & & & $\mathrm{L}$ & 12.4 & - & - & 20 & 23.6 & - \\
\hline 9 & 23 & M & Vertebral fracture & D11, D12 & $\mathrm{R}$ & 10.8 & - & - & 20.4 & 24 & - \\
\hline & & & & & $\mathrm{L}$ & 10.2 & - & - & 20 & 23.8 & - \\
\hline 10 & 41 & $M$ & Vertebral fracture & D11, D12 & $\mathrm{R}$ & 10 & - & - & 18.2 & 20.4 & - \\
\hline & & & & & $\mathrm{L}$ & 10 & - & - & 18 & - & - \\
\hline 11 & 35 & $\mathrm{~F}$ & Vertebral fracture & D12 & $\mathrm{R}$ & 9.7 & - & - & 16.2 & 19 & - \\
\hline & & & & & $\mathrm{L}$ & 9.6 & - & - & 16 & 18.8 & - \\
\hline 12 & 63 & $M$ & Disc herniation & D11-12 & $\mathrm{R}$ & 12 & - & - & 21 & - & - \\
\hline & & & & & $\mathrm{L}$ & 12.2 & - & - & 21.2 & - & - \\
\hline 13 & 46 & $M$ & Vertebral fracture & L1 & $\mathrm{R}$ & 10.4 & 13.6 & 26.6 & 21 & - & 39 \\
\hline & & & & & $\mathrm{L}$ & 10.8 & 14.6 & 27 & 20.4 & - & 38.2 \\
\hline 14 & 37 & $\mathrm{~F}$ & Vertebral fracture & L1 & $\mathrm{R}$ & 9.2 & 12.4 & 25 & 16.8 & - & 36 \\
\hline & & & & & $\mathrm{L}$ & 9.6 & 12.8 & 25.8 & 17 & - & 37.4 \\
\hline
\end{tabular}

-=Absent, not evaluable. Abnormal values are in bold.

Recording electrodes (impedance $<5$ $\mathrm{KOhm}$ ) were placed over the spinous process of the fourth lumbar vertebra (L4), referred to the second lumbar vertebra (L2), to record the cauda equina root response; over the spinous process of the 12th thoracic vertebra (T12), referred to the anterior abdomen (Abd), to record the spinal $\mathrm{N} 14$ or $\mathrm{N} 24$ response; at the scalp point $\mathrm{Cz}^{\prime}(2 \mathrm{~cm}$ behind $\mathrm{Cz})$, referred to Fpz, to record the scalp P27 or P40 response. The rationale for this montage has been discussed in detail in a previous study. ${ }^{2}$

NORMATIVE DATA

We used laboratory normative data (table 2) collected from 35 control subjects (age range 19-59, mean 32 (SD11)) for tibial nerve SEPs ${ }^{2}$ and from 20 control subjects (age range 19-47, mean 23.9 (SD 5.2)) for common peroneal nerve SEPs. ${ }^{\circ}$

To assess the conduction time in somatosensory pathways we measured the peak latencies of the following common peroneal nerve SEPs:

Table 2 SEP normal values

\begin{tabular}{|c|c|c|c|c|}
\hline & Mean & $S D$ & Range & $\begin{array}{l}\text { Limit of normal values } \\
\text { (mean }+3 S D)\end{array}$ \\
\hline \multicolumn{5}{|l|}{ Common peroneal nerve: } \\
\hline Cauda equina latency (ms) & 10.4 & 0.7 & $9.6-12.8$ & 12.5 \\
\hline N14 latency (ms) & 13.9 & 0.96 & $12.4-16.4$ & 16.8 \\
\hline P27 latency (ms) & 26.1 & 2.3 & $22.1-30.1$ & 33 \\
\hline $\begin{array}{l}\text { CE-P27 interpeak interval } \\
(\mathrm{ms})^{\star}\end{array}$ & 20 & 1.8 & $17.1-23.8$ & 25.4 \\
\hline \multicolumn{5}{|l|}{ Posterior tibial nerve: } \\
\hline Cauda equina latency (ms) & 18.3 & 1.7 & $14.4-23$ & 24.4 \\
\hline N24 latency (ms) & 22.2 & 1.9 & $18.4-28$ & 27.9 \\
\hline P40 latency (ms) & 38 & 2.7 & $31.2-45.8$ & 46.1 \\
\hline $\begin{array}{l}\text { CE-P40 interpeak interval } \\
(\mathrm{ms}) \dagger\end{array}$ & 19.7 & 1.6 & $16.4-23.4$ & 24.5 \\
\hline
\end{tabular}

${ }^{\star}$ Regression analysis: CE-P27=0.1 $\times$ height+3.9 (correlation coefficient $0.5, \mathrm{R}[2] 24.6 \%$, SEE 1.3).

†Regression analysis: $\mathrm{CE}-\mathrm{P} 40=0.09 \times$ height +3.73 (correlation coefficient $0.48, \mathrm{R}[2] 23.9 \%$, SEE 1.4). cauda equina response (CE), spinal N14, and cortical P27; and of the following tibial nerve SEPs: cauda equina response (CE), spinal N24, and cortical P40. CE-P40 and CE-P27 interpeak intervals were also calculated. Because the CE-P40 and CE-P27 were less significantly correlated with the height of the subjects than were the P40 and P27 latencies, only patients showing the complete loss of cortical responses as well as those who showed definitely prolonged CE-P40 or CE-P27 interpeak values were considered as having abnormal scalp SEPs. ${ }^{2}$

\section{Results}

SEP FINDINGS

The SEPs were abnormal in all patients (table 1). Tibial nerve SEP abnormalities concerned the N24 lumbar response (absent) and the scalp P40 potential (CE-P40 interval prolonged, absent P40). N24 was abnormal in eight patients (14 lower limbs). P40 was abnormal in 11 patients (22 lower limbs). Common peroneal nerve SEP abnormalities concerned the N14 lumbar response (absent) and the scalp P27 potential (CE-P27 interval prolonged, absent P27). N14 was abnormal in 11 patients (20 lower limbs). P27 was abnormal in 11 patients (22 lower limbs).

SEP: RADIOLOGICAL CORRELATION

Of the two patients with cord compression above the 12th thoracic vertebra, one (patient 2) showed normal spinal responses, whereas the other (patient 1) had abnormal spinal responses to tibial as well as common peroneal nerve stimulation.

All 10 patients with lesions involving the 12th thoracic vertebra showed abnormal N14 response to common peroneal nerve stimula- 
tion (fig 1); moreover, five patients $(3,4,5,10$, and 12) also had abnormal $\mathrm{N} 24$ response to tibial nerve stimulation.

Lastly, the two patients with lesions involving the first lumbar vertebra always showed normal spinal responses to common peroneal nerve stimulation and abnormal spinal responses to tibial nerve stimulation (fig 2).
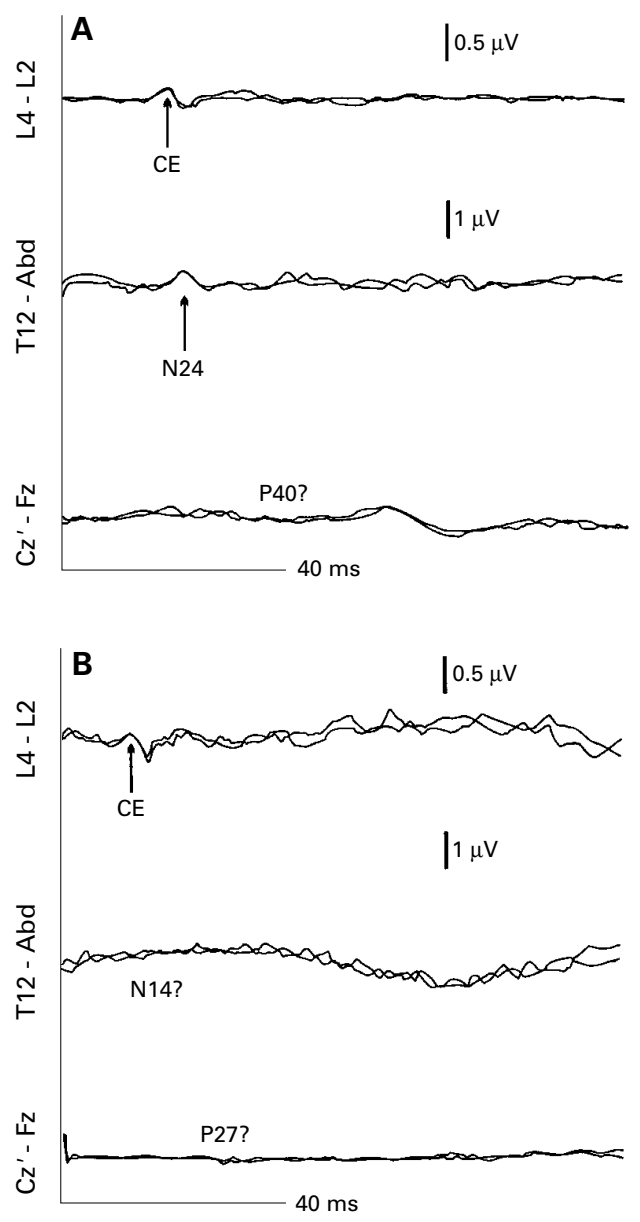

Figure 1 Patient no 8 . (A) traces obtained on two successive runs of 2024 run are superimposed. L4-L2: fourth lumbar vertebra referred to the second lumbar vertebra; T12-Abd: 12 th thoracic vertebra referred to an anterior abdominal electrode located slightly above the umbilicus (Ant); $C z^{\prime}-F z$ : electrode located 2 $\mathrm{cm}$ behind $\mathrm{C} z$ referred to the forehead. Negativity is upward. The latencies of the cauda equina (CE) and N24 responses are within normal limits, whereas the P40 scalp response is absent. (B) left common peroneal nerve

SEPs. Same abbreviations as in $(A)$. The latency of the cauda equina (CE) response is within normal limits, whereas both spinal (N14) and scalp (P27) responses are absent. (C) sagittal T2 weighted image of the thoracic cord MRI. The herniation of the T11-T12 disc with cord compression is evident at the level of the 12 th vertebral body.
SEP: CLINICAL CORRELATION

Absent N14 after common peroneal nerve stimulation correlated significantly with reduced patellar reflex (Fisher's test, $\mathrm{p}=0.012$ ). Absent N24 correlated significantly with reduced ankle reflex (Fisher's test, $p=0.023$ ).

\section{Discussion}

This study shows that the recording of spinal responses after multisegmental lower limb stimulation can improve the SEP localisation power in focal lesions of the lumbosacral cord. We have found a low percentage of $\mathrm{N} 24$ abnormalities after tibial nerve stimulation (50\%), whereas the combined utilisation of tibial and common peroneal nerve stimulation allowed us to detect abnormalities of the spinal response in all but one patient. All our patients had post-traumatic fractures or acute disc herniations, involving, in most cases, the thoracic rather than the lumbar spine. Although the correspondence between vertebral bodies and cord myelomeres is highly variable, it is generally agreed that lumbar myelomeres are located at the level of the last thoracic vertebra, whereas sacral myelomeres correspond to the first lumbar vertebra. ${ }^{9}$ As the dorsal root innervation of the common peroneal nerve is from lumbar myelomeres, ${ }^{10}$ whereas sacral myelomeres mainly contribute to the tibial nerve, ${ }^{11}$ the high percentage of cord compression at the level of the 12th thoracic vertebra could explain why, in our patients, the spinal response was more often affected after common peroneal nerve than tibial nerve stimulation. Instead, in a previous paper, ${ }^{2}$ we described an abnormal N24 spinal response after tibial nerve stimulation in 10 out of 12 patients with definite lesions of the lumbar enlargement. This discrepancy can be easily explained, keeping in mind that most of these patients had vascular or neoplastic lesions largely involving the whole lumbosacral cord.

DORSAL HORN VERSUS DORSAL COLUMN DYSFUNCTIONS

In theory, scalp SEP abnormalities after multisegmental stimulation could give indirect information on the compression level. For instance, abnormal tibial nerve P40 with normal common peroneal nerve P27 should indicate that somatosensory ascending pathways are involved at more caudal levels. However, this never happened in any of our patients; scalp SEP abnormalities, when present, were always evident after stimulation of both the common peroneal nerve and the tibial nerve. Abnormalities of the scalp response after stimulation of both nerves could suggest that the compression is located at a more rostral level. However, this finding did not give information about whether the cord lesion was located at the level of the lumbar enlargement or above. For instance, we found abnormal common peroneal nerve and tibial scalp SEPs in patients having cord compression involving the 12th thoracic vertebra, as well as in one patient (2) with a more rostral level of compression. Lastly, scalp SEPs did not provide any information when they were 
normal-for example, they were fully normal in three of our patients $(1,13$, and 14), regardless of the compression level (D9-D10 in patient $1, \mathrm{~L} 1$ in patients 13 and 14). The more probable explanation for this finding is that in
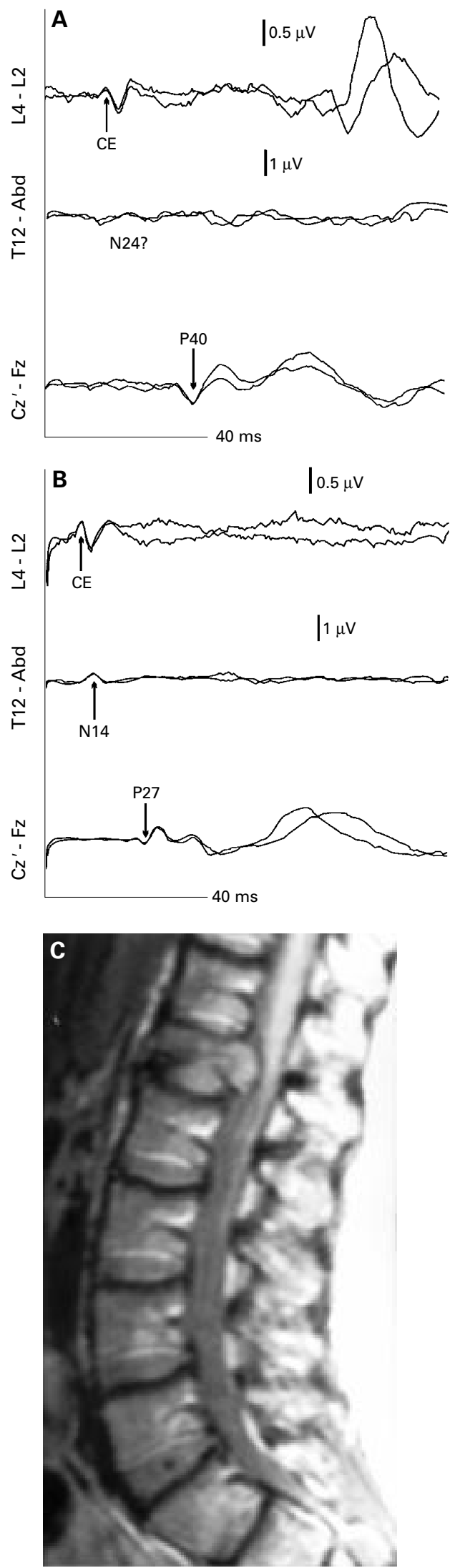

these patients the cord compression functionally involves only the central grey matter, leaving unaffected the somatosensory ascending pathways. Because it is generally agreed that the spinal response is generated by the activation of the lumbar dorsal horn cells, ${ }^{6} 712$ it is conceivable that these patients can show abnormal spinal responses with normal scalp recordings. Such a dissociation between preserved scalp responses and abnormal spinal potentials has been already described in cervical $^{513-15}$ as well as lumbar ${ }^{23}$ myelopathies.

CLINICAL USEFULNESS OF MULTISEGMENTAL SEP RECORDINGS

Lumbar cord compressions obviously entail different management and prognosis than compressions involving only cauda equina roots. Unfortunately, clinical examination fails to localise clear signs of cord involvement. For example, reduced or normal lower limb reflexes without Babinski's sign were found in six of our 14 patients $(1,6,10,12,13$, and 14); moreover, sensory deficit was absent in three patients $(1,5$, and 8$)$. These findings can easily lead to a misdiagnosis of root lesion. Conversely, the neurophysiological study demonstrated in all patients the preservation of the root response with abnormal spinal potentials, thus suggesting that the lesion was primarily located in the spinal cord. The bipolar recording over the lumbar vertebrae makes it possible to cancel the large and widespread cord response and, therefore, to isolate the genuine dorsal root afferent volley ${ }^{16}$; conversely, our Th12 to anterior abdomen array tends to enhance the N24 response, which is generated by a horizontal dipolar source. ${ }^{67}$ Moreover, this technique, by minimising the ECG and muscular noise, makes it possible to obtain a reliable spinal response in all control subjects. If other recording techniques, such as T12 referenced to the knee or to the iliac crest, are used, the spinal response can be lacking in some control subjects, and therefore its loss in patients cannot be used as a marker of clear spinal cord involvement. Thus, this study confirms the usefulness of our recording technique, which clearly separates the root response from the genuine segmental potential generated in the lumbar dorsal horns.

DIAGNOSTIC SENSITIVITY OF SEGMENTAL SPINAL SEPS

Our patients with L1 compression clearly demonstrated dissociation between normal spinal response after common peroneal nerve stimulation and an abnormal spinal response after tibial nerve stimulation. This finding, which was significantly correlated with reduced ankle reflexes, clearly suggested a dysfunction of the sacral rather than lumbar myelomeres. Conversely, all 10 patients with lesions of the thoracic spine, sparing the L1 vertebra, showed abnormality of common peroneal nerve spinal response. Five of these 10 patients also showed abnormal tibial nerve N24. Moreover, one of the two patients with lesions located above the lumbar enlargement (patient 1) had abnormal spinal responses. The more probable explana- 
tion for this finding is that severe compression of rostral segments can cause degeneration of lower myelomeres. ${ }^{17}$ Seen in this light, this finding, indicating that the cord dysfunction involves more cord levels than these directly demonstrated by MRI, could be important for both prognosis and management.

In conclusion, our findings suggest that multisegmental recording techniques, although requiring a longer time and greater care, can provide useful information that is not always forthcoming from either clinical examination or standard neurophysiological techniques.

1 Lehmkühl LD, Dimitrijevic MR, Zidar J. Lumbosacral evoked potential (LSEPs) and cortical somatosensory evoked potentials (SEPs) in patients with lesions of the conus medullaris and cauda equina. Electroenceph clin $\mathrm{Neu}$ rophysiol 1988;71:161-9.

2 Restuccia D, Di Lazzaro V, Valeriani M, et al. N24 spinal response to tibial nerve stimulation and magnetic resonance imaging in lesions of the lumbosacral spinal cord. Neurology 1993;43:2269-75.

3 Restuccia D, Di Lazzaro V, Valeriani M, et al. Spinal responses to median and tibial nerve stimulation and magnetic resonance imaging in intramedullary cord lesions. Neurology 1996;46:1706-14.

4 Valeriani M, Restuccia D, Di Lazzaro V, et al. Recovery after surgery of the spinal N24 SEP in dural arteriovenous malformation of the dorsal cord. Electroenceph Clin Neurophysiol 1995;96:479-82.

5 Ibañez V, Fischer G, Mauguière F. Dorsal horn and dorsal column dysfunction in intramedullary cervical cord tumours. A somatosensory evoked potential study. Brain 1992;115:1209-34

6 Desmedt JE, Cheron G. Spinal and far-field components of human somatosensory evoked potentials to posterior tibial nerve stimulation analysed with oesophageal derivations and non-cephalic reference recording. Electroenceph Clin Neurophysiol 1983;56:635-65.
7 Ratto S, Abbruzzese M, Abbruzzese G, et al. Surface recording of the spinal ventral root disharge in man. Brain 1983;106:897-909.

8 Valeriani M, Restuccia D, Di Lazzaro V, et al. Central nervous system modifications in patients with lesion of the anterior cruciale ligament of the knee. Brain 1996;119: 1751-62

9 Halter JA. Spinal cord evoked potentials recorded at different vertebral levels. In: Dimitrijevic MR, Halter JA, eds. Atlas of human spinal cord evoked potentials. Boston: Butterworth-Heinemann, 1995:39-83.

10 Bannister LH, Berry MM, Collins P, et al. Nervous system. In: Williams PL, Bannister LH, Berry MM, et al, eds. Gray's anatomy. 38th ed. Edinburgh: Churchill Livingstone, 1995:1286-7.

11 Foester O. Spezielle Anatomie und physiologie den peripheren nerve. In: Lewandowsky M, ed. Handbuch den Neurologie, Erganzungsband, zweiter teil. Berlin: Springer, 1929:785-974.

12 Desmedt JE, Cheron G. Prevertebral (oesphageal) recording of subcortical somatosensory evoked potentials in man: the spinal P13 component and the dual nature of the spinal generators. Electroenceph Clin Neurophysiol 1981;52:257gen 75 .

13 Emerson RG, Pedley TA. Effect of cervical spinal cord lesions on early components of the median nerve somatosensory evoked potentials. Neurology 1986;36:20-6.

14 Mauguière $\mathrm{F}$, Ibañez $\mathrm{V}$. The dissociation of early SEP components in lesions of the cervico-medullary junction: a cue for routine interpretation of abnormal cervical responses to median nerve stimulation. Electroenceph Clin Neurophysiol 1985;62:406-20.

15 Restuccia D, Mauguière F. The contribution of median nerve SEPs in the functional assessment of the cervical spinal cord in syringomyelia: a study of 24 patients. Brain 1991;114:361-79.

16 Schiff JA, Cracco RQ, Rossini PM, et al. Spine and scalp somatosensory evoked potentials in normal subjects and patients with spinal cord disease: evaluation of afferent transmission. Electroenceph Clin Neurophysiol 1984;59:37487.

17 Sedgwick EM, El-Negamy E, Frankel H. Spinal cord potentials in traumatic paraplegia and quadriplegia. $\mathcal{F}$ Neurol Neurosurg Psychiatry 1980;43:823-30. 